Case 2

A 50-year-old woman presented with a long history of swelling in the neck. She had a large goitre and signs suggestive of tracheal obstruction. Radiographs of the thoracic inlet showed a superior mediastinal mass pushing the trachea to the left, but with no compression. Anteroposterior and lateral tomograms were normal. Oblique tomograms, however, showed severe narrowing. This was confirmed at operation.

\section{Case 3}

A 65-year-old man presented with a mid-line thyroid swelling. He had a thyroid nodule removed, which on histology proved to be a papillary carcinoma. At reoperation total thyroidectomy was found to be impossible. He was then treated by radioiodine ablation. Four years later he was seen with a fixed mass in the neck. Radiographs taken at the time showed a retrosternal mass extending down from the neck to the pericardium. An increase in his thyroxine to $0.4 \mathrm{mg} /$ day caused regression of his thyroid swelling. Two years later his thyroid swelling again got larger and he developed a slight stridor. Anteroposterior and lateral tomograms were found to be normal. Nevertheless, left oblique tomograms confirmed the presence of severe tracheal narrowing retrosternally and hence a palliative operation was performed and the severe narrowing confirmed.

\section{Comment}

To show a tracheal stenosis the $x$-ray beam should be in the same plane as the stricture. If the $x$-ray beam is directed at any angle other than to the plane of stricture then the stricture will not be shown on the film. In anteroposterior and lateral films the width of the air column remains unchanged but the degree of blackening is reduced because the $x$ rays traverse only a small column of air. The normal air column gives rise to the misleading conclusion that no stricture is present. In fact a review of the anteroposterior and lateral tomograms did show a loss of blackening of the tracheal air column over the length of the stricture in all our cases.

We therefore suggest that in patients with clinical tracheal obstruction and normal anteroposterior and lateral tomograms oblique views should be used.

We thank Dr N A Lewtas and Mr C H Talbot who first suggested the use of oblique tomography and Christine Hackney for secretarial help.

(Accepted 13 October 1978)

\section{Dialysis encephalopathy : recovery after interruption of aluminium intake}

The course of dialysis encephalopathy secondary to aluminium toxicity is usually fatal, ${ }^{2}$ though transplantation has sometimes averted death. We report here a case of dialysis encephalopathy that was reversed after aluminium intake was stopped.

\section{Case report}

From 1973 to 1977 a 71 -year-old woman with chronic glomerulonephritis received maintenance haemodialysis twice a week for seven hours at a time (RP 5 Cupruphane $/ \mathrm{m}^{2}$ haemodialyser). At the start of dialysis the blood phosphorus concentration was $2.9 \mathrm{mmol} / 1(9.0 \mathrm{mg} / 100 \mathrm{ml})$. A daily dose of $5 \mathrm{~g}$ of aluminium hydroxide was prescribed, which reduced the phosphorus concentration to $1.45 \mathrm{mmol} / 1(4.5 \mathrm{mg} / 100 \mathrm{ml})$; blood calcium concentration varied from 2.4 to $2.8 \mathrm{mmol} / 1(9.5$ to $11.5 \mathrm{mg} / 100 \mathrm{ml})$. The average concentration of aluminium in the dialysis fluid after 1976 was $1.8 \mu \mathrm{mol} / \mathrm{l}$ $(4.9 \mu \mathrm{g} / 100 \mathrm{ml})$.

In November 1977 the patient began to develop memory and psychological disturbances. By January 1978 fixation memory was disturbed; she was disorientated in time and space and suffered diurnal somnolence of one to two hours a day, intermittent myoclonic jerks in the arms and legs, and paroxysmal dysarthria. She also had difficulty with mental synthesis and in maintaining attention. No aphasia, difficulty with comprehension, or other focal signs were found. Neurological examination showed brisk reflexes in all four limbs, plantar reflex in flexion bilaterally, and no focal signs. The electroencephalogram (EEG) showed a disturbed pattern (see figure). The blood calcium concentration was $2.5 \mathrm{mmol} / 1(10.0 \mathrm{mg} / 100 \mathrm{ml})$, phosphorus concentration $1.45 \mathrm{mmol} / 1(4.5 \mathrm{mg} / 100 \mathrm{ml})$, and aluminium concentration $14.8 \mu \mathrm{mol} / 1(40 \mu \mathrm{g} / 100 \mathrm{ml})$. Oral aluminium hydroxide administration was stopped, and the dialysis fluid was replaced by another with a lower aluminium content $(0.3 \mu \mathrm{mol} / 1 \quad(0.8 \mu \mathrm{g} / 100 \mathrm{ml}))$. Haemodialysis was performed three times a week for four hours at a time (RP 6 polyacrylonitrile $/ \mathrm{m}^{2}$ haemodialyser).

One month after aluminium intake was interrupted the dysarthria and the myoclonic jerks disappeared and the patient's psychological state and EEG pattern improved (see figure). The aluminium concentration fell to $3.3 \mu \mathrm{mol} / 1(9 \mu \mathrm{g} / 100 \mathrm{ml})$, and calcium and phosphorus concentrations were $2 \cdot 4 \mathrm{mmol} / 1(9.6 \mathrm{mg} / 100 \mathrm{ml})$ and $2.4 \mathrm{mmol} / 1(7 \cdot 4 \mathrm{mg} / 100 \mathrm{ml})$ respectively. By March 1978 all clinical and EEG signs had disappeared and the blood aluminium concentration was $2.5 \mu \mathrm{mol} / 1(6.7 \mu \mathrm{g} / 100 \mathrm{ml})$.

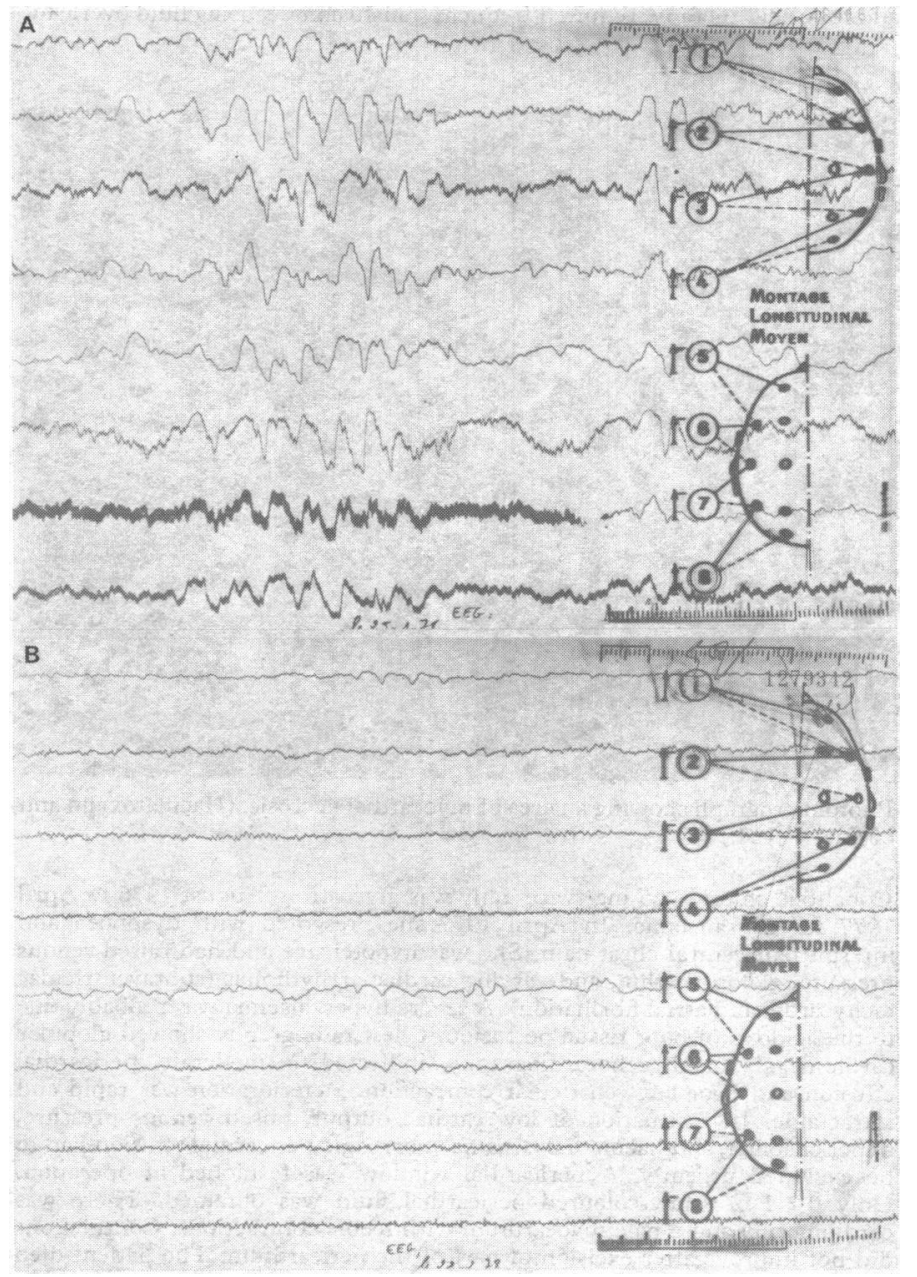

(a) January 1978. EEG showing bilateral synchronous intermittent slow waves. Blood aluminium concentration was $14.8 \mu \mathrm{mol} / 1(40 \mu \mathrm{g} / 100 \mathrm{ml})$. (b) February 1978. Normal EEG. Blood aluminium concentration was $3 \cdot 3 \mu \mathrm{mol} / 1(9 \cdot 0 \mu \mathrm{g} / 100 \mathrm{ml})$.

\section{Comment}

Although dialysis encephalopathy due to aluminium toxicity is usually fatal, ${ }^{12}$ cases that were reversed after aluminium administration was stopped have been reported. ${ }^{4}$ In these cases the encephalopathy began to regress a few weeks, or rarely a few months, after the interruption of aluminium intake; clinical signs were moderate; the EEG pattern was disturbed only after hyperpnoea; and the aluminium concentration was generally under $11 \cdot 1 \mu \mathrm{mol} / \mathrm{l}(30 \mu \mathrm{g} / 100 \mathrm{ml})$. Nevertheless, the relation between the degree of clinical disturbance and the aluminium concentration is not absolute.

Three features in our patient suggested that aluminium toxicity was the cause of the encephalopathy. Firstly, the clinical and EEG signs were identical to those found in other cases of dialysis encephalopathy due to aluminium intoxication. ${ }^{12}$ Secondly, the blood 
aluminium concentration was ten times higher than normal, while no other blood values were abnormal. Finally, the interruption of oral aluminium intake and the reduction of the aluminium concentration in the dialysis fluid were followed by progressive clinical improvement and cure within one month.

It is difficult to determine whether aluminium intoxication is due mainly to digestive absorption after oral intake or to the high concentration of aluminium in dialysis fluid. Generally the concentration of aluminium in dialysis fluid plays an important part in intoxication, ${ }^{25}$ though prolonged ingestion of aluminium salts during chronic renal failure may be responsible for causing encephalopathy. The fact that encephalopathy due to aluminium toxicity may be reversed by stopping aluminium administration indicates the importance of performing repeated measurements of blood aluminium concentrations in patients undergoing haemodialysis and of controlling the aluminium content in dialysis fluid. When considered with EEG and clinical data these measurements may lead to early diagnosis of aluminium toxicity and reversal of the usually fatal course of dialysis encephalopathy.

Requests for reprints should be addressed to: Dr $\mathrm{M}$ Poisson, Clinique Neurologique, Hôpital de la Salpêtrière, Division Mazarin, $47 \mathrm{Bd}$ de l'Hôpital, 75634 Paris Cedex 13.

1 Alfrey, A C, et al, New England fournal of Medicine, 1976, 294, 184.

2 Cartier, F, Nouvelle Presse Médicale, 1978, 7, 97

${ }^{3}$ Buge, A, et al, Nouvelle Presse Médicale, 1978, 7, 2053.

4 Boukari, M, et al, Nouvelle Presse Médicale, 1978, 7, 85.

${ }^{5}$ Platts, M M, et al, British Medical Fournal, 1977, 2, 657.

\section{(Accepted 6 October 1978)}

Clinique Neurologique, Hôpital de la Salpêtrière, Université Paris VI

MICHEL POISSON, MD, professeur agrégé

RAGAY MASHALY, MD, assistant

\section{Occlusion of external carotid artery causing intermittent claudication of the masseter}

Intermittent claudication of the masseter is an unusual but wellrecognised symptom normally associated with temporal arteritis. ${ }^{12}$ We report a case in which it was caused by occlusion of the external carotid artery.

\section{Case report}

A 59-year-old man was admitted to hospital in 1976 after suddenly developing aphasia and inability to control his right hand. These symptoms improved rapidly. Three months previously he had developed cramp-like pain around the angle of the right mandible, which first occurred within two to three minutes of chewing food, especially meat. He had the pain only when chewing. It went almost immediately he stopped chewing, although a dull ache remained for about five minutes. The rate of onset and severity of the pain gradually increased. When he was admitted he could eat meat only if it had been minced. He had had myocardial infarction in 1966 and in 1975. In 1967 he developed intermittent claudication in the calves of both legs and in 1971 he was treated for hypertension. He smoked 40 cigarettes a day.

On examination in hospital the central nervous system was normal and there were no carotid bruits. Neither the temporomandibular joints, the salivary glands, nor the superficial temporal arteries were tender, but pulsations of the right superficial temporal artery were reduced. No significant abnormality was noted in the mouth. The skin of the face and scalp showed no evidence of impaired blood supply. The ESR was $8 \mathrm{~mm}$ in $1 \mathrm{~h}$ and $x$-ray examination of the right temporomandibular joint was normal. An ECG showed no evidence of a recent myocardial infarct. Both carotid bifurcations were visualised by a non-invasive technique using Doppler-shift ultrasound. ${ }^{34}$ This showed a totally occluded external carotid artery with a normal internal carotid artery on the right side and a normal carotid bifurcation on the left side (figure). These findings were confirmed by an arch aortogram. The episode of aphasia and incoordination of the right hand was

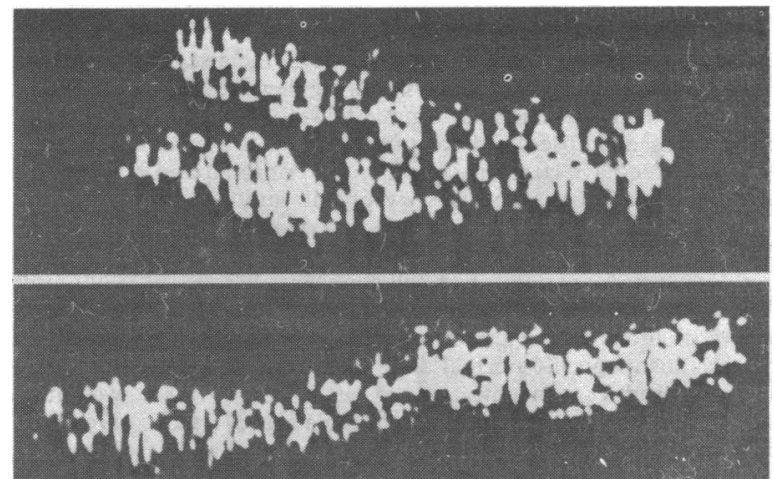

Ultrasound images of both carotid bifurcations taken in supine position (lateral views). Above: normal left junction showing internal carotid inferior to external carotid artery. Below: image of right carotid bifurcation showing patent internal carotid and completely occluded external carotid artery.

thought to be due to a transient ischaemic attack. Although the precise cause of this attack was uncertain he was treated with aspirin and dipyridamole and had no further symptoms. The pain in the jaw remained unchanged for a further three months. It then gradually improved and after another three months he was able to chew without discomfort.

\section{Comment}

We think the pain on eating in this patient was due to intermittent claudication of the masseter. We believe this is the first report of it being caused by occlusive disease of the external carotid artery. It persisted for a total of nine months and we assume that its disappearance was due to a collateral blood supply developing. The patient had generalised occlusive arterial disease. An unusual feature in the extracranial cerebral arteries was the severe disease of the external carotid with no demonstrable disease in the internal carotid artery. Probably atheroma at the origin of the external carotid artery was the principal cause for the total occlusion of this vessel, but possibly it was caused by an embolus from the heart, a result of ischaemic heart disease, rather than by atheroma. An embolus might have also caused the transient ischaemic attack.

We thank Dr R G Gosling, Chairman of the Guy's Hospital Non-invasive Angiology Research Group, for his help and advice.

${ }^{1}$ Russell, R, Quarterly fournal of Medicine, 1959, 28, 471.

2 Bulgen, D Y, and Hagleman, B L, Hospital Medicine, 1976, 2, 39.

${ }^{3}$ Lewis, R R, et al, Stroke, 1978, 9, 465.

4 Beasley, M G, et al, in Doppler Ultrasound in the Study of Central and Peripheral Circulation, ed J P Woodcock and R F Sequeira, chapter 7. Bristol, University of Bristol Press, 1978.

(Accepted 6 October 1978)

Guy's Department of Geriatric and General Medicine, New Cross Hospital, London SE14 SER

R R LEWIS, MB, MRCP, consultant physician

Guy's Hospital, London SE1

M G BEASLEY, BSC, scientific assistant, Non-invasive Angiology Research Group

K S MACLEAN, MD, FRCP, consultant physician

\section{Thrombocytopenia associated with legionnaires' disease}

Legionnaires' disease (LD) commonly presents as an acute and fulminating pneumonia. The causative organism is a Gram-negative pleomorphic bacillus. We report a case which was associated with a transient thrombocytopenia and cerebellar ataxia for which no other cause was found. 